\title{
A novel source of genetic variation in ryegrasses (Lolium multiflorum, L. perenne)
}

\author{
Lutful Hassan, \\ R. N. Jones* and \\ U. K. Posselt $\dagger$
}

* Department of Agricultural Sciences, University College of Wales, Aberystwyth SY23 3DD, Wales, U.K. $\uparrow$ Landessaatzuchtanstalt, Universität Hohenheim, Federal Republic of Germany.

A short period of colchicine treatment at the seedling stage induces changes in the capacity for tillering, vegetative growth and flowering time in inbred lines of Lolium multiflorum. The changes are heritable and are observable in the selfed-seed generation following that in which the treatment was given. Information is also given to confirm such changes in an additional ten inbred lines of Lolium perenne.

\section{INTRODUCTION}

In previous studies in which we have used colchicine as a chromosome doubling agent to produce tetraploids from diploid inbred lines of perennial ryegrass (Lolium perenne) we have observed that the colchichine treatment itself induces heritable changes in the undoubled diploids that were used as controls (Hague and Jones, 1987; Francis and Jones, 1989). The changes involved characters of agronomic significance such as tiller number and fresh and dry weight of leaf material. In the lines investigated so far we have found that these chages varied in their magnitude between lines, and that they were directional in that vegetative production was either increased or else the differences between the treated and untreated controls were nonsignificant. The changes were not random. We have further demonstrated that in perennial ryegrass these colchicine-induced changes are heritable, and that they are transmitted undiminished through a selfed-seed generation (Francis and Jones, 1989). In this publication we present new results for colchicine-induced heritable variations in Italian reygrass ( $L$. multiflorum), and we also confirm the results for $L$. perenne using ten additional inbred lines that have not been previously studied.

\section{MATERIALS AND METHODS}

The Italian ryegrass lines originate from experimental material produced by Professor G. Kobabe,
University of Göttingen and the perennial ryegrass lines are from the inbred material which was originally produced at Hohenheim by Utz and Oettler (1978). The L. perenne lines have their origin in the German ryegrass varieties Odengrün and Odenwälder. In both cases it can be assumed that we are dealing with pure breeding homozygous lines.

Seeds from ten lines of Italian ryegrass and ten lines of perennial ryegrass were "sown" on moist filter paper in petri dishes in October 1986. The petri dishes were placed in a refrigerator at $4^{\circ} \mathrm{C}$ for one week to aid germination. When the seedlings had grown to $2-3 \mathrm{~cm}$ some of them were treated by total immersion in 0.2 per cent aqueous colchicine for $3 \mathrm{hrs}$ at room temperature, and others were immersed in water as the untreated controls. After washing and recovery from treatment the two groups of seedlings were planted in John Innes Compost and grown on in plastic multitrays in a heated greenhouse for two weeks. The survival rate of the colchicine-treated material was of the order of 65 per cent.

At 7 weeks of age the plants were transferred to 5-inch pots in John Innes Compost and grown on to flowering in an unheated glasshouse. Flowering occurred in May-June 1987 and all of the plants were then bagged for self-pollination. The colchicine treated plants were mixoploid, with a mixture of $2 \times$ and $4 \times$ tillers, whereas the control plants were wholly diploid.

Seeds from the selfed plants were grown again without further treatment in November 1987. At 


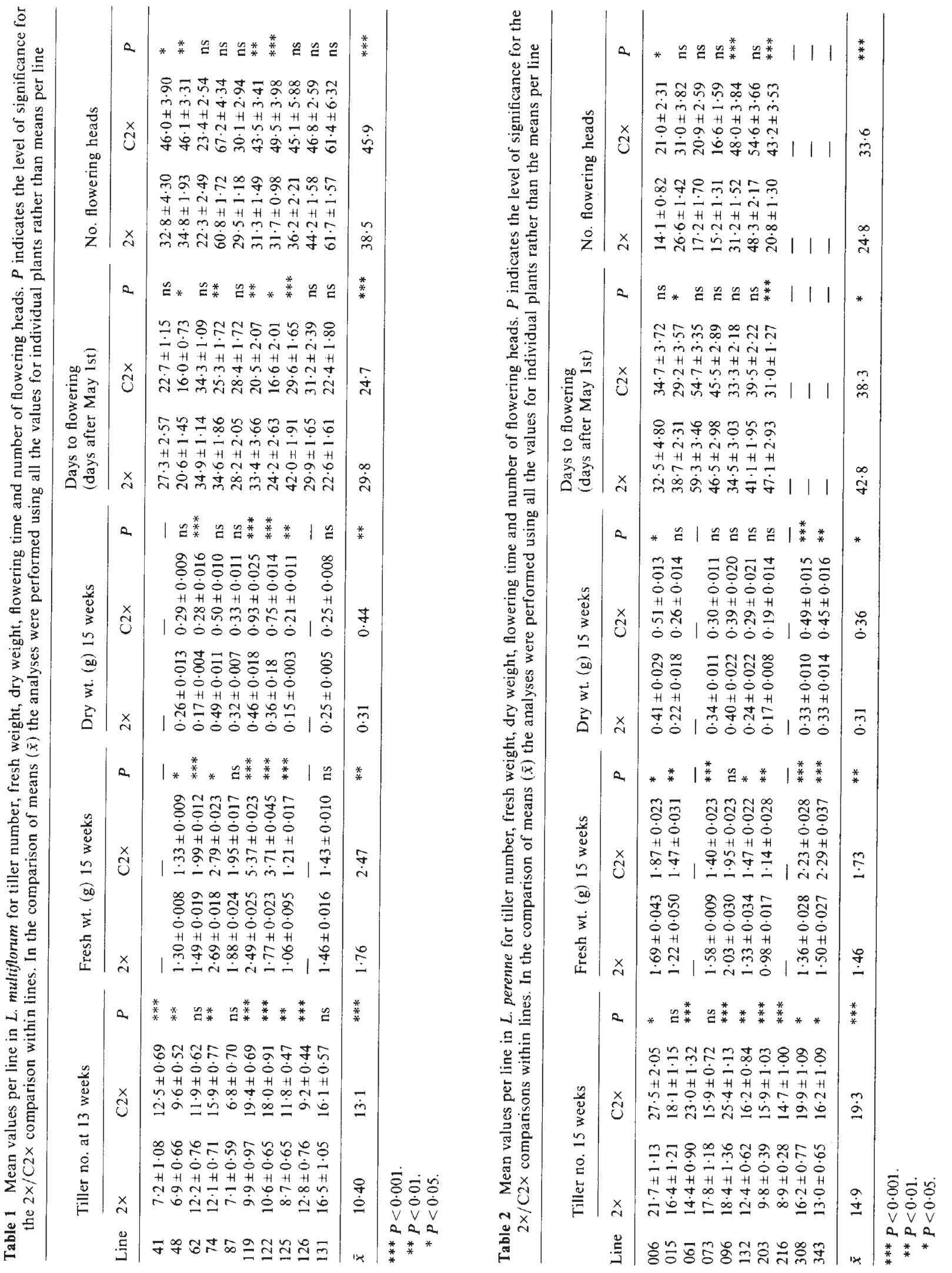


the multitray stage roots were taken from the seedlings of the treated material and were analysed cytologically to distinguish between the diploids and tetraploids. The treated diploids were kept, and ten plants from each of the ten lines of both species were grown on in 5-inch pots in an unheated glasshouse together with their "isogenic" diploid controls. The number of vegetative tillers per plant was counted at 13 weeks after germination for $L$. multiflorum and at 15 weeks for $L$. perenne, and fresh weight and dry weights of leaf material were determined at 15 weeks. Observations were also made on flowering time, which was taken as the date on which three spikelets were seen to have emerged from three separate inflorescences (expressed as number of days after May $1 \mathrm{st}$ ), and the total number of flowering heads. For the fresh and dry weight determinations only four plants were used in each line, and dry weight was taken after keeping fresh leaf material in an oven at $80^{\circ} \mathrm{C}$ overnight.

The nomenclature we are using is the same as before (Hague and Jones, 1987; Francis and Jones, 1989). The untreated diploid lines are referred to as the $2 \times$ material and the colchicine-treated diploids as the $\mathrm{C} 2 \times$ material. Plants belonging to the generation in which the treatment was given are known as the CT0 generation, and those derived from the selfed-seed of the CT0 are known as the CT1 gneration. In this investigation we have only made observations on the CT1 plants.

\section{RESULTS}

The results for the observations on the five characters used, together with levels of significance for comparisons between the $2 \times$ and $\mathrm{C} 2 \times$ treatments, are given in table 1 for L. multiflorum and in table 2 for $L$. perenne.

\section{Lolium multiflorum}

Seven out of the ten lines show a significantly different tiller number for the $\mathrm{C} 2 \times$ compared with the $2 \times$ (table 1$)$. In six of these lines the $\mathrm{C} 2 \times$ have more tillers than the $2 \times$, and the mean over all lines also gives a significantly higher number of $\mathrm{C} 2 \times$ tillers. Lines 119 and 122 have particularly striking effects, and line 126 is contrasting in that it breaks the pattern found in our earlier studies on $L$. perenne where all $\mathrm{C} 2 \times$ had significantly more tillers than the $2 \times$.

Fresh and dry weights were determined for eight of the ten lines. Six out of the eight lines have increased fresh weights for the $\mathrm{C} 2 \times$ compared with $2 \times$ (table 1 ), and the most pronounced effects are again in lines 119 and 122 . The dry weight pattern closely follows that for fresh weight (table 1). Although only four plants per line were used for the fresh and dry weight determinations significance is obtained for quite small mean differences between $2 \times$ and $\mathrm{C} 2 \times$ because the error variation is so low.

In five of the ten lines the $\mathrm{C} 2 \times$ plants flowered significantly earlier than $2 \times$, and in four lines the $\mathrm{C} 2 \times$ has significantly more flowering heads than the $2 \times$ (table 1$)$.

Variances about the mean showed no significant differences between $2 \times$ and $\mathrm{C} 2 \times$ for any of the characters in any of the lines.

\section{Lolium perenne}

The pattern for vegetative tillers in $L$. perenne confirms that found in our previous studies with a different set of lines, that is to say the $\mathrm{C} 2 \times$ material shows an enhanced level of tiller production over the $2 \times$. Eight of the ten lines studied here in the CT1 generation show significantly more tillers for the $\mathrm{C} 2 \times$ compared with the "isogenic" $2 \times$ material, and the mean values across all lines are also significantly different (table 2).

Fresh and dry weights were again determined in only eight lines. There are significant differences between treatments in seven out of the eight lines, and in six of the lines the $\mathrm{C} 2 \times$ has a greater fresh weight value than the $2 \times$ (table 2 ). The pattern for dry weights is similar to that for fresh weight, but the levels of significance are lower (table 2). For both fresh and dry weights the most marked treatment differences are in lines 308 and 343 .

In two out of seven lines studied the $\mathrm{C} 2 \times$ flowered significantly earlier than their "isogenic" $2 \times$ controls and three out of seven lines had a significantly higher number of flowering heads (table 2).

Tests on variances show no consistent trend, and significant effects are found only for tiller number, where the $\mathrm{C} 2 \times$ variance exceeds that of the $2 \times$ in lines $203(P<0.05)$ and line $216(P<$ $0.01)$; and days to flowering where the $2 \times$ has a higher variance than the $\mathrm{C} 2 \times(P<0.05)$.

\section{DISCUSSION}

The observations presented in this paper, together with those given earlier (Hague and Jones, 1987; Francis and Jones, 1989), have now firmly estab- 
lished that a short burst of colchicine treatment given to one-week old seedlings has significant heritable effects upon the growth and development of diploid inbred lines of two species of ryegrasses. In total we have now studied 28 inbred lines, 18 in $L$. perenne and ten in $L$. multiflorum. In $L$. perenne we have shown stable treatment effects over 8 years of vegetative propagation, by tillering, and in both $L$. perenne and $L$. multiflorum the induced changes are transmitted through at least one generation of sexual reproduction by selfing.

The magnitude and distribution of the effects amongst the lines is variable, and at the one extreme we are dealing with induced heritable changes in agronomic characters of the order of two-fold increase in the number of vegetative tillers and in the production of fresh and dry leaf matter material( line 119). Such changes beg the question of their potential for usefulness in crop plant improvement, and the extent to which other crop plant species may be manipulated in the same way. At a later stage we will present results to show that these colchicine-induced changes apply also to cell and chloroplast organisation as well as to aspects of chromosome behaviour at meiosis.

Thus far we have not found these effects in outbred population material, and neither have we yet been able to adequately analyse them in reciprocal crosses. The precise treatment conditions also remain to be ascertained, as does the stability of the changes through further generations of selfing.

The causes of this novel source of genetic variation remains unknown. One possibility is that the mutagenic effect of colchicine has induced multiple point mutations of the kind described in Sorghum (Franzke and Ross, 1957; Erichsen et al., 1962; Foster et al., 1961a, b; Sanders et al., 1962), and in Barley (Gilbert and Patterson, 1965), and that the resulting heterozygosity has led to enhanced phenotypic vigour. This possibility has not presented itself in this material, however, and there are no obvious major gene mutation segregating out in the $\mathrm{Ct} 1$ generation of the treated material. The variances of the $\mathrm{C} 2 \times$ lines are also not consistently greater than those of the $2 \times$, and in some lines they are smaller. Another aspect to be considered is that of genome re-organisation in the form of amplification of certain DNA sequences of the kind described in some flax genotrophs (Walbot and Cullis, 1985; Cullis, 1986).

Acknowledgement The project was supported by The Commonwealth Scholarship Commission.

\section{REFERENCES}

CUllis, C. A. 1986. Phenotypic consequences of environmentally induced changes in plant DNA. Trends in Genetics, 2, 307-309.

ERICHSEN, A. W., FRANZKE, C. J., SANDERS, M. E. AND ROSS, J. G. 1962. Colchicine induced mutations in Sorghum which affect qualitative characters. $J$. Hered., 53, 304-308.

FOSTER, A. E., ROSS, J. G. AND FRANZKE, C. J. 1961 a. Proximity of mutated genes in colchicine-induced mutants of Sorghum. Crop Sci., 1, 72-75.

FOSTER, A. E., ROSS, J. G. AND FRANZKE, C. J. 1961 b. Estimates of the number of mutated genes in a colchicine-induced mutant of Sorghum. Crop Sci., 1, 272-276.

FRANCIS, AMANDA AND JONES, R. N. 1989. Heritable nature of colchicine induced variation in diploid Lolium perenne. Heredity , 62, 407-410.

FRANZKE, C. J. AND ROSS, J. G. 1957. A lineal series of mutants induced by colchicine treatment. J. Hered., 48, 47-50.

HAGUE, L. M. AND JONES, R. N. 1987. Cytogenetics of Lolium perenne. 4. Colchicine induced variation in diploids. Theor. Appl. Genet., 74, 233-241.

Gilbert, S. K. AND PATterson, F. L. 1965. Colchicineinduced mutants of "Decatur" barley. Crop Sci., 5, 44-47.

SANDERS, M. E., FRANZKE, C. J. AND ROSS, J. G. 1962. Genetic studies of nontrue-breeding mutants of Sorghum obtained after colchicine treatment. Crop Sci., 2, 387-390.

WALBOT, V. AND CULLIS, C. A. 1985. Rapid genomic changes in higher plants. Ann. Rev. Plant Physiol., 36, 317-396.

UTZ, H. F. AND OETTLER, G. 1978. Performances of inbred lines and their top crosses in perennial ryegrass (Lolium perenne L.). Z. Pflanzenzüchtg., 80, 223-229. 